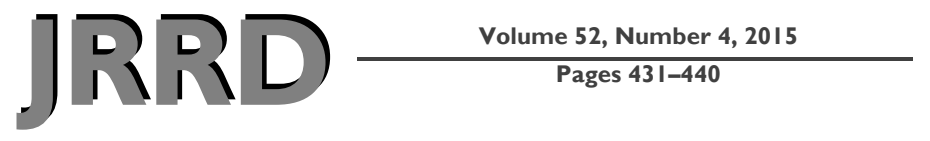

\title{
Endogenous pain inhibition is unrelated to autonomic responses in acute whiplash-associated disorders
}

\author{
Margot De Kooning, MSc; ${ }^{1-2}$ Liesbeth Daenen, PhD; ${ }^{1-2}$ Nathalie Roussel, PhD; ${ }^{1,3}$ Patrick Cras, PhD, MD; ${ }^{2,4}$ \\ Ronald Buyl, PhD; ${ }^{5}$ Kelly Ickmans, PhD; ${ }^{1}$ Filip Struyf, PhD; ${ }^{1,3}$ Jo Nijs, PhD ${ }^{1^{*}}$ \\ ${ }^{1}$ Pain in Motion Research Group, Departments of Human Physiology and Physiotherapy, Faculty of Physical Educa- \\ tion and Physiotherapy, Vrije Universiteit Brussel, Brussels, Belgium; ${ }^{2}$ Faculty of Medicine and Health Sciences, Uni- \\ versity of Antwerp, Antwerp, Belgium; ${ }^{3}$ Pain in Motion Research Group, Department of Rehabilitation Sciences and \\ Physiotherapy (REVAKI), Faculty of Medicine and Health Sciences, University of Antwerp, Antwerp, Belgium; \\ ${ }^{4}$ Department of Neurology, Antwerp University Hospital, Antwerp, Belgium; ${ }^{5}$ Department of Biostatistics and Medical \\ Informatics, Vrije Universiteit Brussel, Brussels, Belgium
}

\begin{abstract}
Patients with acute whiplash-associated disorder (WAD) demonstrate an inefficient endogenous pain inhibition and may experience a dysfunction in autonomic nervous system reactivity to pain. This study compared the autonomic response to painful stimuli between patients with acute and chronic WAD and healthy controls. In addition, the role of the autonomic nervous system for explaining inefficient endogenous pain inhibition was examined in acute WAD. Seventeen patients with acute WAD, 30 patients with chronic WAD, and 31 healthy controls participated in an experiment evaluating the autonomic nervous system at rest and during painful stimuli. Skin conductance and heart rate variability (HRV) parameters were monitored continuously during conditioned pain modulation. A significant autonomic response to pain was present for skin conductance and two HRV parameters in all experimental groups. There was an interaction effect in the skin conductance response to pain but not in HRV responses in any of the groups. In patients with acute WAD, no significant correlations were present between pain, pressure pain thresholds, pain inhibition, and any of the autonomic parameters. This study refutes autonomic dysfunction at rest and in response to pain in acute WAD. The dysfunctional conditioned pain modulation appears unrelated to autonomic responses to pain.
\end{abstract}

Key words: acute whiplash, autonomic nervous system, central sensitization, experimental pain, heart rate variability, pain modulation, posttraumatic stress reaction, skin conductance, stress reaction, whiplash-associated disorder.

\section{INTRODUCTION}

A whiplash trauma is an acceleration-deceleration trauma of the neck mainly caused by a motor vehicle collision. Persistent pain and disability is common, with up to 50 percent of patients with acute whiplash-associated disorder (WAD) not fully recovering and continuously experiencing multiple symptoms such as chronic neck pain, fatigue, dizziness, concentration difficulties, and

\footnotetext{
Abbreviations: ANOVA $=$ analysis of variance, $\mathrm{BDI}=$ Beck Depression Inventory, CPM = conditioned pain modulation, $\mathrm{HF}=$ high-frequency power, HRV = heart rate variability, IES = Impact of Event Scale, LF = low-frequency power, NDI = Neck Disability Index, PCS = Pain Catastrophizing Scale, PPT = pressure pain threshold, PTSR = posttraumatic stress reaction, PVAQ = Pain Vigilance and Awareness Questionnaire, RMSSD = root-mean-square of successive differences between interbeat intervals, SD = standard deviation, SDNN = standard deviation of interbeat intervals, $\mathrm{TS}=$ temporal summation, $\mathrm{WAD}=$ whiplashassociated disorder.

*Address all correspondence to Jo Nijs, PhD; Vrije Universiteit Brussel, Medical Campus Jette, Building F-Kine, Laarbeeklaan 103, BE-1090 Brussels, Belgium; +3224774489; fax: +3226292876. Email: Jo.Nijs@vub.ac.be http://dx.doi.org/10.1682/JRRD.2014.06.0154
} 
headaches [1-3]. Radiological findings or cervical dysfunctions do not account for the development of chronic WAD [4-5]. On the other hand, increasing evidence exists that WAD is caused by the presence of sensitization of the central nervous system or hyperexcitability of the brain and spinal cord (reviewed in Van Oosterwijck et al. [6]). This hyperexcitability of the central nervous system leads to generalized hypersensitivity to a variety of stimuli such as bright light, touch, and odors and is characterized by widespread pain, concentration difficulties, fatigue, and stress intolerance [7]. Another aspect of central sensitization is the dysfunction in pain inhibition [8]. Patients with chronic WAD have decreased pressure pain thresholds (PPTs) in response to exercise [9] and demonstrate dysfunctional pain inhibition [10], providing evidence for the presence of central sensitization in this population.

Besides the presence of central sensitization, the stress response system can influence pain through several neurophysiologic mechanisms; sympathetic activation may lead to lowered sensory and pain thresholds [11]. Passatore and Roatta stated that enhanced sympathetic activation may lead to central sensitization and to the development of chronic pain [12]. They describe how enhanced sympathetic activation affects muscle spindle function, muscle microcirculation, and muscle contractile properties, leading to chronic pain in patients with WAD. Dysfunctions in the autonomic nervous system (e.g., enhanced activity of the sympathetic nervous system) have been observed in chronic widespread pain syndromes characterized by central sensitization (e.g., fibromyalgia [13-15]) but not in more localized pain conditions (e.g., lower back pain [16]). McLean et al. hypothesized that increased acute autonomic activity and variations in hypothalamus-pituitary-adrenalaxis activity after a motor vehicle collision would predict an increased likelihood of subsequently developing WAD [17]. Indeed, diminished vasoconstrictive response, an indication of sympathetic nervous system activation, has a predictive value in the transition from acute to chronic WAD [18]. If autonomic dysfunction is present in patients with acute WAD, it might be related to pain and the dysfunctional pain inhibition.

Besides a whiplash trauma, another common sequelae after a motor vehicle collision is posttraumatic stress reaction (PTSR) [19]. Musculoskeletal pain, headache, and difficulties with short-term memory and concentration are described in both WAD and PTSR [17-20], and an overlap between these conditions has been suggested [14,21]. Available evidence suggests a relationship between acute PTSR and the development of chronic WAD. In patients with WAD, pain and PTSR are closely related soon after the trauma [20-21]. The presence of PTSR is associated with an increased risk of persistent pain and disability [21-24], but the question remains whether PTSR is related to an autonomic nervous system dysfunction in acute WAD.

Given the previously outlined evidence, the question arises whether dysfunction in autonomic nervous system functioning is a feature of WAD in the acute phase. If there is a dysfunction in the autonomic nervous system in people with acute WAD, is this related to the presence of PTSR and is there an interaction with pain inhibition? Therefore, the goal of this study was to compare the autonomic response to painful stimuli between patients with acute WAD, chronic WAD, and healthy controls and to explore the role of the autonomic nervous system in explaining inefficient endogenous pain inhibition in acute WAD together with the possible role of PTSR.

\section{METHODS}

\section{Study Design}

A case-control study design with repeated measures and real-time monitoring of various autonomic parameters was used to evaluate whether patients with acute WAD show a dysfunctional autonomic response to pain compared with patients with chronic WAD and healthy controls and whether autonomic reactivity to pain is related to conditioned pain modulation (CPM) of heterotopic noxious conditioning stimulation in people with acute WAD. This study was part of a larger project. The results of sensorimotor incongruence and an in-depth discussion of dysfunction in pain inhibition can be found in Daenen et al. [25]

\section{Participants}

Subjects experiencing acute WAD were recruited within 1 mo postwhiplash via the emergency department of a Flemish Red Cross medical care unit and the Antwerp University Hospital and through primary care medical practices. Subjects with chronic WAD were recruited through advertisement on the Internet and from the medical database of a Flemish Red Cross medical care unit. Chronicity was defined as complaints persisting for at 
least 3 mo. A variety of recruitment procedures were used in order to prevent recruitment bias [26]. The inclusion criteria for the acute and chronic WAD group were experiencing symptoms resulting from a whiplash trauma and fulfilling the diagnostic criteria of WAD grade I to III as defined by the Quebec Task Force classification [1]. Subjects were excluded if they had cervical fractures or dislocation, and thus were classified as WAD grade IV [1], or if they reported a previous history of whiplash trauma.

Healthy control participants were recruited through the local university staff and through family and acquaintances of the researchers. The control participants had no knowledge about the study hypotheses and were not allowed to participate if they had ever experienced a whiplash trauma or experienced pain or neck-shoulderarm symptoms in the previous 6 mo. Further, persons with a chronic disease, pain condition, or psychiatric disorder (depression, anxiety, etc.) were excluded from study participation.

Patients were asked to discontinue analgesic and anti-inflammatory drugs $48 \mathrm{~h}$ before testing. All participants were instructed to avoid physical exertion and to refrain from consuming nicotine, alcohol, and caffeine $24 \mathrm{~h}$ before testing. Further exclusion criteria were pregnancy and cardiovascular or neurological disease.

\section{Procedure}

Before study participation, participants were asked to read an information leaflet and to sign the written informed consent. The study protocol, information leaflet, and informed consent were approved by the Human Research Ethics Committee of the Antwerp University Hospital. A standardized questionnaire was used to collect personal characteristics and accident- and health-related information. Afterward, participants filled out a battery of questionnaires. Next, they participated in an experiment to evaluate CPM (paradigm of heterotopic noxious conditioning stimulation). Simultaneously with this pain measurement, autonomic functions were continuously registered to measure the autonomic response to pain.

\section{Measurements}

\section{Self-Reported Questionnaires}

Self-reported questionnaires were used to assess pain, disability, psychosocial factors, pain cognition, and posttraumatic stress. The Neck Disability Index (NDI) was used to evaluate participants' neck pain and disability (score out of 100). The NDI was found reliable and valid [27]. A score for posttraumatic stress was obtained by the Impact of Event Scale (IES). It has been validated for the measure of stress reactions after a traumatic experience [28] and has been used in previous studies concerning patients with whiplash injury [5,23]. The IES score was dichotomized into "no-mild PTSR" (IES score $<26$ ) and "moderate-severe PTSR" (IES score $\geq 26$ ) [29]. Other questionnaires were the Pain Catastrophizing Scale (PCS) [30], Pain Vigilance and Awareness Questionnaire (PVAQ), [31] and Beck Depression Inventory (BDI) [32].

\section{Experimental Pain Measurement: Conditioned Pain Modulation}

PPTs were measured with an analog Fisher algometer (Force Dial model FDK 40, Wagner Instruments; Greenwich, Connecticut) at the right upper trapezius (middle point between the spinal process of thoracic level 1 and the most lateral part of the acromion) and at the right $\mathrm{M}$. quadriceps (middle point between groin and the most proximal part of the patella). These points were chosen to examine the affected area (neck and shoulder) and a segmental unrelated area (thigh). In order to determine PPTs at each location, pressure was gradually increased at a rate of $1 \mathrm{~kg} / \mathrm{s}$ until the subject reported first onset of pain. The threshold was taken as the mean of two consecutive measurements (30 s interval). The PPT technique was found to be reliable [33]. At each location, temporal summation (TS) was provoked by means of 10 consecutive (1 s interval) pressure pulses at the previously determined PPT. Pressure was gradually increased at a rate of $2 \mathrm{~kg} / \mathrm{s}$ to the determined PPT and maintained on that point for $1 \mathrm{~s}$ before being released. The participants rated the intensity and unpleasantness of the pain of the first, fifth, and tenth pulse on a verbal numerical rating scale (where $0=$ no pain and $10=$ worst possible pain). Afterward, a rest period of 5 min was allowed before investigating the CPM mechanism. This CPM mechanism was induced by inflating an occlusion cuff at the subject's left arm to a painful intensity (conditioning stimulus). The occlusion cuff was inflated at a rate of $20 \mathrm{~mm} \mathrm{Hg} / \mathrm{s}$ until "the first sensation of pain" was reported and maintained for $30 \mathrm{~s}$. Afterward, the subject was asked to rate the pain intensity of the cuff inflation on a verbal numerical rating scale. Next, the cuff inflation was increased or decreased until pain intensity at the left arm was rated as $3 / 10$ on the verbal rating scale. The previously described TS 
assessment was then repeated during maintenance of this cuff inflation. The increase in pain intensity from the first to tenth pulse is used as a measure for TS. CPM effect was described as the difference in TS (the difference in increase in pain intensity) prior to and during cuff inflation. The test-retest reliability of the experimental noxious protocol was described previously [34].

\section{Autonomic Function Measurements}

Continuous recordings of skin conductance and cardiovascular parameters were obtained using the NeXus 10 MK-II (Mind Media BV; Herten, the Netherlands) with blood volume pulse and skin conductance sensors and processed using BioTrace+ software version V2010A (Mind Media BV). All sensors were attached at the participant's right hand. The skin conductance sensor uses two Ag-AgCL electrodes that are secured by Velcro straps to the tip of the index and ring fingers. The sensor is sensitive to very small relative changes in skin conductance (1/1000 microsiemens). The blood volume pulse sensor uses fingertip photoplethysmography to measure heart rate and monitor relative blood volume. Heart rate variability (HRV) can be acquired through this sensor and generates reliable data [35]. The blood volume pulse sensor was placed on the little finger. For artifact removal, a prolonged interbeat interval was defined as being either longer than $1,400 \mathrm{~ms}$ or longer than 150 percent of the value of the preceding interbeat interval. A short interbeat interval was defined as being either shorter than $400 \mathrm{~ms}$ or shorter than 50 percent of the value of the preceding interbeat interval.

HRV measures in the time domain included standard deviation (SD) of interbeat intervals (SDNN) and rootmean-square of successive differences between interbeat intervals (RMSSD). In addition, power spectrum of the Pintervals, the time interval between two consecutive pulses, was derived by Fast Fourier transformation using Kubios HRV software version 2.0 (University of Eastern Finland; Kuopio, Finland). It is suggested that lowfrequency power (LF) $(0.04-0.15 \mathrm{~Hz})$ of HRV is mediated by both sympathetic and parasympathetic modulations. High-frequency power (HF) $(0.15-0.4 \mathrm{~Hz})$ of HRV is mainly under control of the vagal nerve. The LF/HF ratio is an indicator of cardiac sympathetic modulation and sympathovagal balance [36]. Measures of total spectral power and very low frequency from short recordings are physiologically ambiguous, and for this reason, their use is not recommended by the task force [36]. The length of the recordings was between 2 and 5 min for each experimental stage. Therefore, total spectral power and very low frequency were not analyzed. For all parameters, mean values in each experimental stage were calculated. To determine the autonomic reactivity, the difference in value was calculated between the experimental phase during cuff inflation and at rest for all autonomic parameters.

\section{Statistical Analysis}

Statistical analysis was performed in SPSS version 20.0 (IBM Corporation; Armonk, New York). All data were checked for normal distribution using the Kolmogorov-Smirnov test. HRV parameters in the frequency domain-LF, HF, and LF/HF ratio-were not normally distributed and were logarithmically transformed. A $3 \times$ 3 (group $\times$ time) analysis of variance (ANOVA) with repeated measures was used. Main effect of group (acute WAD, chronic WAD, and healthy controls), main effect of time (rest, TS prior to cuff inflation, and TS during cuff inflation), and group $\times$ time interaction was evaluated for all dependent variables (skin conductance, heart rate, SDNN, RMSSD, LF, HF, and LF/HF ratio). A Pearson correlation analysis was used to assess the relation between the dependent variables and CPM or PPTs. Significant level for correlations was set to 0.01 to correct for type I errors. Since sex distribution was not equal in the three groups, sex was used as covariate in both the ANOVA and correlation analysis.

\section{RESULTS}

\section{Group Characteristics}

All persons from whom autonomic measurements were available were included in this study. Seventeen patients with acute WAD (7 women and 10 men), 30 patients with chronic WAD (24 women and 6 men), and 31 healthy controls (24 women and 7 men) volunteered for the study. The mean \pm SD age was $41.4 \pm 7.49 \mathrm{yr}$ for the acute WAD group, $43.6 \pm 9.44 \mathrm{yr}$ for the chronic WAD group, and $43.45 \pm 15.87 \mathrm{yr}$ for the control group. The groups were comparable in terms of age $(p>0.05)$. The chronic WAD group and the control group did not differ in terms of sex or educational level $(p>0.05)$. The acute WAD group differed in sex distribution from the other two groups, with a greater number of male participants $(p<$ 0.05 ). The 17 patients with acute WAD included in this study did not differ in clinical characteristics from the 
13 patients with acute WAD from which we failed to collect data of autonomic function (age, sex, PPTs, NDI, IES, PCS, BDI, and PVAQ all $p>0.05$ ).

Table 1 presents the mean scores for neck disability, depression, pain catastrophizing, pain vigilance and awareness, and posttraumatic stress per group. In the acute WAD group, 5 participants reported mild pain and disability (NDI score between 10 and 28) and 9 participants reported moderate or severe pain and disability (NDI score $\geq 30$ ) [27]. In the chronic WAD group, 1 participant reported mild pain and disability and 29 participants were classified as having moderate or severe pain and disability. Compared with the acute and chronic WAD group, the control group scored lower on the PCS, PVAQ, and BDI. There was no difference in pain catastrophizing, pain vigilance, or depressive thoughts between the acute and chronic WAD group. However, the acute WAD group reported lower pain and disability compared with the control group as measured with the NDI $(p=0.007)$. Of the 17 patients with acute WAD, 2 (11.8\%) with acute WAD reported moderate or severe PTSR (IES score $\geq 26$ ) in contrast with 10 out of 30 (33.3\%) in the chronic WAD group.

\section{Pressure Pain Thresholds and Conditioned Pain Modulation}

Table 2 summarizes the results for PPTs and CPM. Mean PPTs at the upper trapezius and the quadriceps were $4.27 \pm 2.59$ and $6.09 \pm 2.6 \mathrm{~kg} / \mathrm{cm}^{2}$ for the acute WAD group, $3.26 \pm 1.38$ and $5.25 \pm 2.5 \mathrm{~kg} / \mathrm{cm}^{2}$ for the chronic WAD group, and $4.94 \pm 1.53$ and $6.7 \pm 2.44 \mathrm{~kg} / \mathrm{cm}^{2}$ for the healthy control group, respectively. Mean PPTs in the acute WAD group did not differ from the control group or from the chronic WAD group at any place $(p>0.05)$.

Table 1.

Group characteristics and scores of self-reported measurements.

\begin{tabular}{|c|c|c|c|}
\hline Variable & Acute WAD $(n=17)$ & Chronic WAD $(n=30)$ & Control $(n=31)$ \\
\hline \multicolumn{4}{|l|}{ Sex $(n)$} \\
\hline Female & 7 & 24 & $24^{*}$ \\
\hline Male & 10 & 6 & 7 \\
\hline Age (yr) & $41.4 \pm 7.49$ & $43.6 \pm 9.44$ & $43.45 \pm 15.87$ \\
\hline Neck Disability Index (score) & $33.18 \pm 16.70$ & $44.27 \pm 13.39$ & $3.48 \pm 4.19^{\dagger}$ \\
\hline Beck Depression Inventory (score) & $8.06 \pm 5.32$ & $15.47 \pm 9.41$ & $2.68 \pm 2.63^{\ddagger}$ \\
\hline Pain Vigilance and Awareness Questionnaire (score) & $32.76 \pm 10.47$ & $34.38 \pm 12.73$ & $23.70 \pm 12.17^{\ddagger}$ \\
\hline Impact of Event Scale (score) & $12.53 \pm 12.89$ & $20.37 \pm 16.57$ & - \\
\hline \multicolumn{4}{|c|}{$\begin{array}{l}\text { Note: Group comparisons were performed using Bonferonni post hoc analysis of one-way analysis of } \\
\text { standard deviation. } \\
\text { *Significant difference between acute WAD group and other two groups. } \\
\left.{ }^{\dagger} \text { Significant difference between acute WAD group, chronic WAD group, and control group ( } p \leq 0.05\right) \text {. } \\
{ }^{\ddagger} \text { Significant difference between two WAD groups and control group }(p \leq 0.05) \text {. } \\
\text { WAD = whiplash-associated disorder. }\end{array}$} \\
\hline
\end{tabular}

Table 2.

Pressure pain thresholds (PPTs) and conditioned pain modulation (CPM).

\begin{tabular}{lccc}
\hline \multicolumn{1}{c}{ Variable } & Acute WAD $(\boldsymbol{n}=\mathbf{1 7})$ & Chronic WAD $(\boldsymbol{n}=\mathbf{3 0})$ & Control $(\boldsymbol{n}=\mathbf{3 1})$ \\
\hline PPT & & $3.26 \pm 1.38$ & $4.94 \pm 1.53^{*}$ \\
$\quad$ Trapezius & $4.27 \pm 2.59$ & $5.25 \pm 2.5$ & $6.7 \pm 2.44^{*}$ \\
Quadriceps & $6.09 \pm 2.6$ & & \\
CPM & & & $1.52 \pm 1.15^{*}$ \\
Trapezius & $1.18 \pm 1.67$ & $1.00 \pm 1.60$ & $1.52 \pm 0.93^{*}$ \\
Quadriceps & $0.88 \pm 1.58$ & $0.07 \pm 1.48$ & \\
\hline
\end{tabular}

Note: Group comparisons were performed using one-way analysis of variance and corrected for sex. Values displayed are mean \pm standard deviation.

${ }^{*}$ Significant difference between chronic WAD group and other two groups.

WAD $=$ whiplash-associated disorder. 
Mean CPM effect on TS at the upper trapezius and the $\mathrm{M}$. quadriceps were $1.18 \pm 1.67$ and $0.88 \pm 1.58$ for the acute WAD group, $1.00 \pm 1.60$ and $0.07 \pm 1.48$ for the chronic WAD group, and $1.52 \pm 1.15$ and $1.52 \pm 0.93$ for the control group, respectively. The CPM effect at the quadriceps muscle in the acute WAD group tended to be reduced compared with the control group $(p=0.054)$ and higher than the chronic WAD group ( $p=0.053)$. CPM at the upper trapezius in the acute WAD group did not differ from the other groups $(p>0.05)$. A detailed discussion of the pain measurements can be found in Daenen et al. [25].

\section{Autonomic Function: Comparison Between Patients with Whiplash-Associated Disorder and Healthy Controls}

\section{Autonomic Response to Painful Stimuli}

The Figure shows the autonomic parameters in each experimental stage. The autonomic parameters (skin conductance, HR, SDNN, RMSSD, LF, HF, and LF/HF ratio) at rest were compared between the three groups and corrected for sex. No significant differences for any of the parameters was observed between the three groups at rest $(p>0.05)$. All groups reacted to painful stimuli with a significant increase in skin conductance (time effect: $F=38.737, p=0.001)$. Further, there was a significant group $\times$ time interaction effect for skin conductance $(F=3.619, p=0.02)$. Also, there was a significant decrease of SDNN and RMSSD in response to painful stimuli (SDNN: $F=6.073, p=0.003$; RMSSD: $F=$ $3.353, p=0.04$ ) but no group or interaction effects were present for these parameters. The heart rate and levels of LF, HF, and LF/HF ratio did not change significantly with painful stimuli because there was no time, group, or group $\times$ time interaction effect. The Figure presents levels of autonomic parameters during different stages. Together, this indicates that there is an autonomic response to the painful stimuli but that only minor variations in response between the groups are present.

\section{Correlations of Autonomic Measurements with Pain, \\ Pressure Pain Thresholds, Conditioned Pain Modulation, and Posttraumatic Stress Reaction}

Associations between the autonomic measurements and the PPTs were analyzed in the three groups separately and corrected for sex. PPTs were unrelated to any of the autonomic measurements in the acute WAD group ( $p>$ $0.01)$ as well as in the control group ( $p>0.01)$. Likewise,
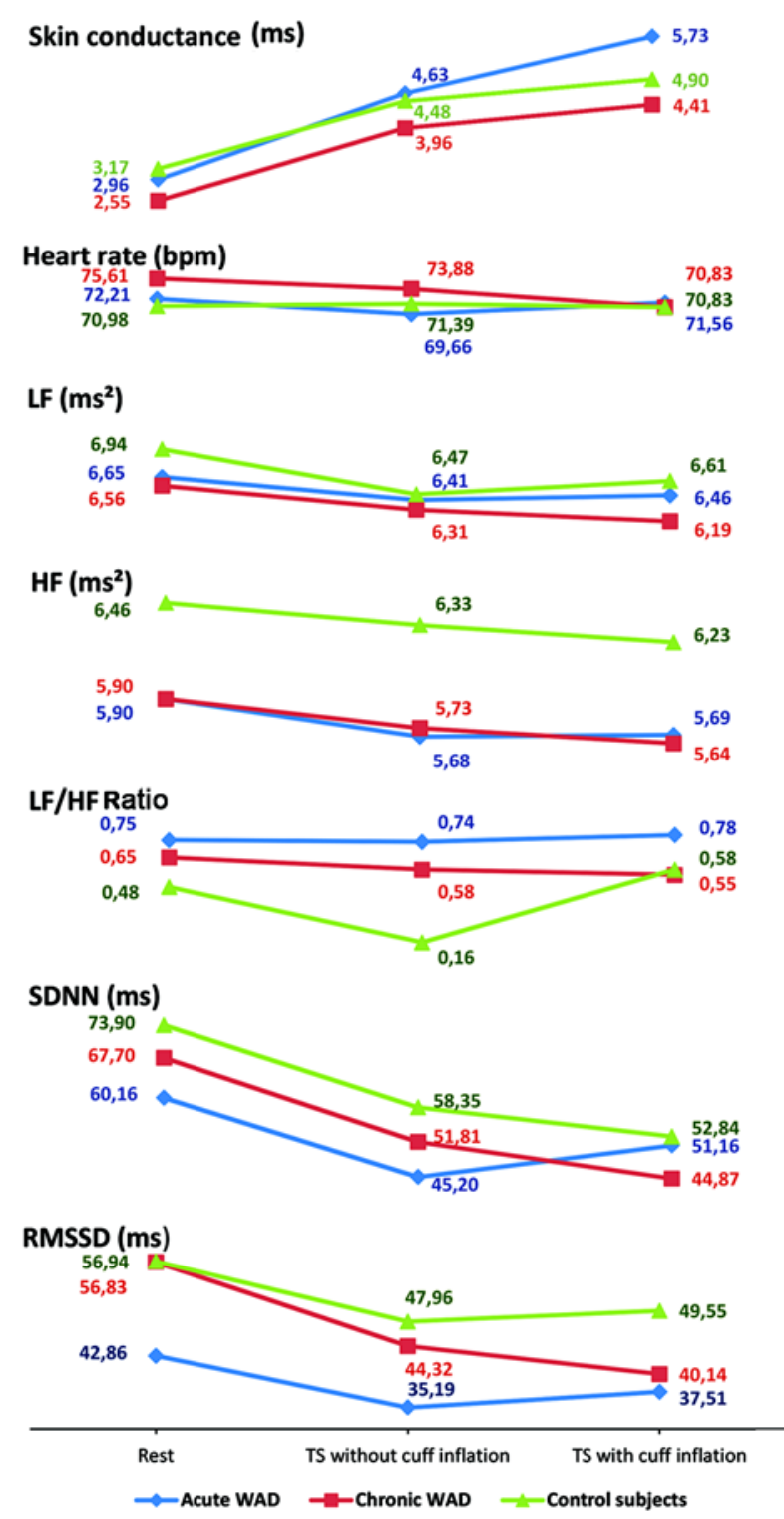

Figure.

Significant interaction effect is present for skin conductance ( $p=0.02$ ), and effect of time is present for autonomic parameters of skin conductance between all three stages $(p<0.01)$. Effect of time is present for standard deviation of interbeat intervals (SDNN) between rest and temporal summation (TS) without cuff inflation and between rest and TS with cuff inflation ( $p<$ 0.01 ). Effect of time is present for root-mean-square of successive differences between interbeat intervals (RMSSD) between rest and TS without cuff inflation and between rest and TS with cuff inflation $(p<0.05)$. Repeated-measures analysis of variance and post hoc analysis; mean values for each phase. bpm = beats per minute, HF = high-frequency power, LF = lowfrequency power, WAD = whiplash-associated disorder. 
no significant associations between the autonomic parameters and CPM data were found in both the acute WAD group and the control group $(p>0.01)$. Otherwise, in chronic WAD, PPTs at the M. trapezius correlated with heart rate at rest $(r=0.480, p=0.008)$ and LF at rest correlated with CPM ( $r=-0.473, p=0.01)$. Further, in this chronic WAD group, SDNN reactivity (the difference in SDNN between rest and pain during cuff inflation) also correlated with CPM ( $r=0.494, p=0.006)$. As for the questionnaires, no significant associations between the results of the NDI or IES and the autonomic parameters were found in any of the groups $(p>0.01)$.

\section{DISCUSSION}

This study examined the autonomic response to pain and the association between autonomic nervous system functioning, pain, and endogenous analgesia in patients with acute and chronic WAD. The results demonstrate similar autonomic basal levels and a similar autonomic response to pain in patients with acute and chronic WAD and healthy controls for cardiac parameters but a slightly stronger response of acute WAD to pain for the autonomic parameter skin conductance. The dysfunctional endogenous analgesia (as typically seen in patients with acute and chronic WAD) and lowered PPTs appear unrelated to autonomic responses to pain in acute WAD.

All three groups demonstrated a similar basal level of autonomic activity at rest, indicating no autonomic dysfunction at rest in acute WAD. When experimental pain was applied, the study data revealed a significant reaction of skin conductance, SDNN, and RMSSD to pain in all groups. This indicates that the pain stimuli, as applied here, were able to induce a physiological stress reaction. This supports the validity of the applied experimental pain stimuli. The autonomic reaction to pain was similar in the three groups for the cardiac parameters (heart rate, SDNN, RMSSD, LF, HF, and LF/HF ratio) but the groups showed a different response for skin conductance. Increased sympathetic tone leads to sweating, which in turn results in an elevation of skin conductance. Skin conductance is a more sensitive parameter in response to pain than HRV parameters [37]. HRV parameters may not be sensitive enough to demonstrate minor fluctuations in autonomic response to pain. Indeed these findings refute the hypothesis of an overall dysfunction of the autonomic response to pain in WAD. In previous analyses comparing chronic WAD with healthy controls for autonomic reactivity to pain, no difference in skin conductance response was found [38]. The current analysis adds a group of patients with acute WAD and displays a difference in skin conductance response between the groups. As seen in the Figure, the group with acute WAD displays a slightly stronger response of skin conductance to pain. This raises the possibility that patients with acute WAD demonstrate a dysfunctional autonomic response to pain. However, the difference in skin conductance reactivity between the groups is minor. Even though this difference is statistically significant, its clinical relevance is questionable. On top of this, skin conductance is the only parameter for which a difference in reaction is found; namely, no differences in HRV parameter reactivity were present. Larger studies are necessary to evaluate whether this different skin conductance response is actually clinically relevant.

These results for HRV measurements in chronic WAD are in line with the findings of Kalezic et al.; namely, no differences in HRV parameter reactivity were found in people with chronic WAD compared with healthy controls [39]. To the best of our knowledge, this is the first report of HRV measurements in an acute WAD population. Hence, no comparisons can be made with earlier findings. The present results indicate that patients with acute WAD do not present a distinctive dysfunction of the autonomic response to experimental pain. These findings refute previous suggestions that dysfunctional autonomic responses contribute to the persistent pain and disability in this population [12,40-41].

Autonomic sympathetic activation may lead to lower sensory and pain thresholds [11]. In addition, Mclean et al. suggested a relationship between stress response systems and dysregulation of descending pain modulating pathways in poststress pain states, such as WAD [17]. Within this study, the acute and chronic WAD groups demonstrated different relations between PPTs and CPM and autonomic parameters. In the chronic WAD group, higher heart rate at rest was associated with higher PPTs at the upper trapezius, while a larger CPM effect at the upper trapezius was associated with lower LF at rest. None of these associations were present in the acute WAD group or in the healthy control group, where pain measurements appeared to be unrelated to autonomic parameters.

Due to the limited number of patients with acute WAD that experienced PTSR (2 persons), it was not possible to compare the autonomic response between 
patients with and without PTSR. Examining the association between levels of PTSR, as measured with the IES, and autonomic parameters demonstrated no significant relation between PTSR and any of the autonomic or pain measurements in any group. This contrasts with findings of Sterling and Kenardy, who demonstrated a relation between PTSR and a diminished sympathetic response as well as an association between the presence of PTSR and lower PPTs in a whiplash population [5]. In Sterling and Kenardy, PTSR was present in 31.5 percent of the patients with acute WAD compared with only 11.8 percent in the present study. It might be possible that the relations between PTSR, autonomic responses, and pain thresholds are stronger in the subgroup with higher PTSR levels, which might explain why they are not present in this current study.

Several methodological issues need to be taken into account when considering the conclusions made from this study. This study was part of a larger project [25] in which 30 patients with acute WAD originally participated. Due to technical difficulties, the autonomic data of only 17 patients could be retrieved. As a result of this, the number of participants in the acute WAD group was limited to 17.

Also, note that the present study used fingertip photoplethysmography to obtain HRV data. Although this technique generates reliable data [35], it is sensitive to movement artifacts. Therefore, similar research using electrocardiogram to assess HRV is warranted to further explore the role of the autonomic nervous system in patients with WAD.

The present study is the first to explore the interactions between the autonomic response to experimental pain, endogenous analgesia, and PTSR in patients with acute WAD. Importantly, this is the first study measuring various autonomic variables in real-time during the administration of experimental pain in patients with acute WAD.

\section{CONCLUSIONS}

The autonomic response to painful stimuli does not differ between patients with acute WAD, patients with chronic WAD, and healthy controls for autonomic controlled cardiac parameters, but the three groups did demonstrate a different skin conductance response to pain. Overall, this study does not support the hypothesis that autonomic activity or reactivity strongly interferes with pain and CPM in the acute WAD population.

\section{ACKNOWLEDGMENTS}

\section{Author Contributions:}

Study concept and design: J. Nijs, N. Roussel, P. Cras, L. Daenen, F. Struyf.

Acquisition of data: L. Daenen.

Analysis and interpretation of data: M. De Kooning, K. Ickmans. Drafting of manuscript: M. De Kooning.

Critical revision of manuscript for important intellectual content: M. De Kooning, L. Daenen, N. Roussel, P. Cras, R. Buyl, K. Ickmans, F. Struyf, J. Nijs.

Statistical analysis: R. Buyl, M. De Kooning.

Study supervision: L. Daenen.

Financial Disclosures: The authors have declared that no competing interests exist.

Funding/Support: This material was based on work supported by the research council of the University of Antwerp (grant 41/FA020000/3/ 3995).

Institutional Review: Before study participation, participants were asked to read an information leaflet and to sign the written informed consent. The study protocol, information leaflet, and informed consent were approved by the Human Research Ethics Committee of the Antwerp University Hospital.

Participant Follow-Up: Participants will not be informed personally, but a message will be placed in the leaflet of the patient support group together with the main conclusion and the reference for the article once published. Patients were informed of their individual results after study participation.

\section{REFERENCES}

1. Spitzer WO, Skovron ML, Salmi LR, Cassidy JD, Duranceau J, Suissa S, Zeiss E. Scientific monograph of the Quebec Task Force on Whiplash-Associated Disorders: Redefining "whiplash” and its management. Spine. 1995; 20(8 Suppl):1S-73S. [PMID:7604354]

2. Barnsley L, Lord S, Bogduk N. Whiplash injury. Pain. 1994;58(3):283-307. [PMID:7838578] http://dx.doi.org/10.1016/0304-3959(94)90123-6

3. Lovell ME, Galasko CS. Whiplash disorders-a review. Injury. 2002;33(2):97-101. [PMID:11890909]

http://dx.doi.org/10.1016/S0020-1383(01)00111-5

4. Nordin M, Carragee EJ, Hogg-Johnson S, Weiner SS, Hurwitz EL, Peloso PM, Guzman J, van der Velde G, Carroll LJ, Holm LW, Côté P, Cassidy JD, Haldeman S. Assessment of neck pain and its associated disorders: Results of the Bone and Joint Decade 2000-2010 Task Force on Neck Pain and its Associated Disorders. J Manipulative Physiol 
Ther. 2009;32(2 Suppl):S117-40. [PMID:19251060]

http://dx.doi.org/10.1016/j.jmpt.2008.11.016

5. Sterling M, Kenardy J. The relationship between sensory and sympathetic nervous system changes and posttraumatic stress reaction following whiplash injury-a prospective study. J Psychosom Res. 2006;60(4):387-93.

[PMID:16581363]

http://dx.doi.org/10.1016/j.jpsychores.2005.08.016

6. Van Oosterwijck J, Nijs J, Meeus M, Paul L. Evidence for central sensitization in chronic whiplash: A systematic literature review. Eur J Pain. 2013;17(3):299-312.

[PMID:23008191] http://dx.doi.org/10.1002/j.1532-2149.2012.00193.x

7. Nijs J, Van Houdenhove B, Oostendorp RA. Recognition of central sensitization in patients with musculoskeletal pain: Application of pain neurophysiology in manual therapy practice. Man Ther. 2010;15(2):135-41.

[PMID:20036180]

http://dx.doi.org/10.1016/j.math.2009.12.001

8. Meeus M, Nijs J, Van de Wauwer N, Toeback L, Truijen S. Diffuse noxious inhibitory control is delayed in chronic fatigue syndrome: An experimental study. Pain. 2008; 139(2):439-48. [PMID:18617327]

http://dx.doi.org/10.1016/j.pain.2008.05.018

9. Van Oosterwijck J, Nijs J, Meeus M, Van Loo M, Paul L. Lack of endogenous pain inhibition during exercise in people with chronic whiplash associated disorders: An experimental study. J Pain. 2012;13(3):242-54.

[PMID:22277322]

http://dx.doi.org/10.1016/j.jpain.2011.11.006

10. Daenen L, Nijs J, Roussel N, Wouters K, Van Loo M, Cras

P. Dysfunctional pain inhibition in patients with chronic whiplash-associated disorders: An experimental study. Clin Rheumatol. 2013;32(1):23-31. [PMID:22983264] http://dx.doi.org/10.1007/s10067-012-2085-2

11. Caceres C, Burns JW. Cardiovascular reactivity to psychological stress may enhance subsequent pain sensitivity. Pain. 1997;69(3):237-44. [PMID:9085297] http://dx.doi.org/10.1016/S0304-3959(96)03289-7

12. Passatore M, Roatta S. Influence of sympathetic nervous system on sensorimotor function: Whiplash associated disorders (WAD) as a model. Eur J Appl Physiol. 2006; 98(5):423-49. [PMID:17036216]

http://dx.doi.org/10.1007/s00421-006-0312-8

13. Martínez-Lavín M, Hermosillo AG, Mendoza C, Ortiz R, Cajigas JC, Pineda C, Nava A, Vallejo M. Orthostatic sympathetic derangement in subjects with fibromyalgia. J Rheumatol. 1997;24(4):714-18. [PMID:9101507]

14. Raj SR, Brouillard D, Simpson CS, Hopman WM, Abdollah H. Dysautonomia among patients with fibromyalgia: A noninvasive assessment. J Rheumatol. 2000;27(11):2660-65. [PMID:11093450]
15. Furlan R, Colombo S, Perego F, Atzeni F, Diana A, Barbic F, Porta A, Pace F, Malliani A, Sarzi-Puttini P. Abnormalities of cardiovascular neural control and reduced orthostatic tolerance in patients with primary fibromyalgia. J Rheumatol. 2005;32(9):1787-93. [PMID:16142879]

16. Gockel M, Lindholm H, Niemistö L, Hurri H. Perceived disability but not pain is connected with autonomic nervous function among patients with chronic low back pain. J Rehabil Med. 2008;40(5):355-58. [PMID:18461260] http://dx.doi.org/10.2340/16501977-0172

17. McLean SA, Clauw DJ, Abelson JL, Liberzon I. The development of persistent pain and psychological morbidity after motor vehicle collision: Integrating the potential role of stress response systems into a biopsychosocial model. Psychosom Med. 2005;67(5):783-90. [PMID:16204439] http://dx.doi.org/10.1097/01.psy.0000181276.49204.bb

18. Sterling M, Jull G, Vicenzino B, Kenardy J, Darnell R. Physical and psychological factors predict outcome following whiplash injury. Pain. 2005;114(1-2):141-48.

[PMID:15733639]

http://dx.doi.org/10.1016/j.pain.2004.12.005

19. Kuch K, Cox BJ, Evans R, Shulman I. Phobias, panic, and pain in 55 survivors of road vehicle accidents. J Anxiety Disord. 1994;8:181-87. http://dx.doi.org/10.1016/0887-6185(94)90015-9

20. Sterling M, Jull G, Vicenzino B, Kenardy J. Characterization of acute whiplash-associated disorders. Spine. 2004; 29(2):182-88. [PMID:14722412] http://dx.doi.org/10.1097/01.BRS.0000105535.12598.AE

21. Drottning M, Staff PH, Levin L, Malt UF. Acute emotional response to common whiplash predicts subsequent pain complaints-Prospective study of 107 subjects sustaining whiplash injury. Nord J Psychiatry. 1995;49(4):293-300. http://dx.doi.org/10.3109/08039489509011919

22. Sterling M, Kenardy J, Jull G, Vicenzino B. The development of psychological changes following whiplash injury. Pain. 2003;106(3):481-89. [PMID:14659532] http://dx.doi.org/10.1016/j.pain.2003.09.013

23. Kongsted A, Bendix T, Qerama E, Kasch H, Bach FW, Korsholm L, Jensen TS. Acute stress response and recovery after whiplash injuries. A one-year prospective study. Eur J Pain. 2008;12(4):455-63. [PMID:17900949] http://dx.doi.org/10.1016/j.ejpain.2007.07.008

24. Buitenhuis J, de Jong PJ, Jaspers JP, Groothoff JW. Relationship between posttraumatic stress disorder symptoms and the course of whiplash complaints. J Psychosom Res. 2006;61(5):681-89. [PMID:17084147] http://dx.doi.org/10.1016/j.jpsychores.2006.07.008

25. Daenen L, Nijs J, Cras P, Wouters K, Roussel N. Changes in pain modulation occur soon after whiplash trauma but are not related to altered perception of distorted visual feedback. Pain Pract. 2014;14(7):588-98. 
JRRD, Volume 52, Number 4, 2015

\section{[PMID:24118839]}

http://dx.doi.org/10.1111/papr.12113

26. Nijs J, Inghelbrecht E, Daenen L, Hachimi-Idrissi S, Hens L, Willems B, Roussel N, Cras P, Wouters K, Bernheim J. Recruitment bias in chronic pain research: Whiplash as a model. Clin Rheumatol. 2011;30(11):1481-89.

[PMID:21853277] http://dx.doi.org/10.1007/s10067-011-1829-8

27. Vernon H, Mior S. The Neck Disability Index: A study of reliability and validity. J Manipulative Physiol Ther. 1991; 14(7):409-15. [PMID:1834753]

28. van der Ploeg E, Mooren TT, Kleber RJ, van der Velden PG, Brom D. Construct validation of the Dutch version of the Impact of Event Scale. Psychol Assess. 2004;16(1):16-26. [PMID:15023089] http://dx.doi.org/10.1037/1040-3590.16.1.16

29. Horowitz M, Wilner N, Alvarez W. Impact of Event Scale: A measure of subjective stress. Psychosom Med. 1979; 41(3):209-18. [PMID:472086] http://dx.doi.org/10.1097/00006842-197905000-00004

30. Osman A, Barrios FX, Kopper BA, Hauptmann W, Jones J, O'Neill E. Factor structure, reliability, and validity of the Pain Catastrophizing Scale. J Behav Med. 1997;20(6):589-605. [PMID:9429990] http://dx.doi.org/10.1023/A:1025570508954

31. Roelofs J, Peters ML, McCracken L, Vlaeyen JW. The Pain Vigilance and Awareness Questionnaire (PVAQ): Further psychometric evaluation in fibromyalgia and other chronic pain syndromes. Pain. 2003;101(3):299-306.

[PMID:12583873] http://dx.doi.org/10.1016/S0304-3959(02)00338-X

32. Osman A, Kopper BA, Barrios F, Gutierrez PM, Bagge CL. Reliability and validity of the Beck Depression Inventory-II with adolescent psychiatric inpatients. Psychol Assess. 2004;16(2):120-32. [PMID:15222808] http://dx.doi.org/10.1037/1040-3590.16.2.120

33. Cathcart S, Pritchard D. Reliability of pain threshold measurement in young adults. J Headache Pain. 2006;7(1):21-26. [PMID:16440140] http://dx.doi.org/10.1007/s10194-006-0265-7

34. Cathcart S, Winefield AH, Rolan P, Lushington K. Reliability of temporal summation and diffuse noxious inhibitory control. Pain Res Manag. 2009;14(6):433-38. [PMID:20011713]

35. Selvaraj N, Jaryal A, Santhosh J, Deepak KK, Anand S. Assessment of heart rate variability derived from finger-tip photoplethysmography as compared to electrocardiography. J Med Eng Technol. 2008;32(6):479-84.

[PMID:18663635] http://dx.doi.org/10.1080/03091900701781317
36. Task Force of the European Society of Cardiology and the North American Society of Pacing and Electrophysiology. Heart rate variability. Standards of measurement, physiological interpretation, and clinical use. Eur Heart J. 1996; 17(3):354-81. [PMID:8737210]

37. Treister R, Kliger M, Zuckerman G, Goor Aryeh I, Eisenberg E. Differentiating between heat pain intensities: The combined effect of multiple autonomic parameters. Pain. 2012;153(9):1807-14. [PMID:22647429] http://dx.doi.org/10.1016/j.pain.2012.04.008

38. De Kooning M, Daenen L, Cras P, Gidron Y, Roussel N, Nijs J. Autonomic response to pain in patients with chronic whiplash associated disorders. Pain Physician. 2013;16(3): E277-85. [PMID:23703426]

39. Kalezic N, Noborisaka Y, Nakata M, Crenshaw AG, Karlsson S, Lyskov E, Eriksson PO. Cardiovascular and muscle activity during chewing in whiplash-associated disorders (WAD). Arch Oral Biol. 2010;55(6):447-53.

[PMID:20413105]

http://dx.doi.org/10.1016/j.archoralbio.2010.03.015

40. McLean SA. The potential contribution of stress systems to the transition to chronic whiplash-associated disorders. Spine. 2011;36:S226-32.

http://dx.doi.org/10.1097/BRS.0b013e3182387fb4

41. Sterling M, McLean SA, Sullivan M, Elliott J, Butenhuis J, Kamper SK. Potential processes involved in the initiation and maintenance of whiplash-associated disorders: Discussion paper 3. Spine. 2011;36:S322-29.

http://dx.doi.org/10.1097/BRS.0b013e318238853f

Submitted for publication June 24, 2014. Accepted in revised form February 24, 2015.

This article and any supplementary material should be cited as follows:

De Kooning M, Daenen L, Roussel N, Cras P, Buyl R, Ickmans K, Struyf F, Nijs J. Endogenous pain inhibition is unrelated to autonomic responses in acute whiplash-associated disorders. J Rehabil Res Dev. 2015;52(4):431-40. http://dx.doi.org/10.1682/JRRD.2014.06.0154

ResearcherID: Margot De Kooning, MSc: G-3125-2015

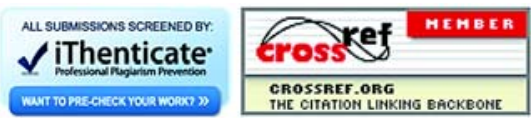

